\title{
Gender Disparities in Self-concept, Attitude and Perception in Physics and Chemistry
}

\author{
Inzahuli Samuel Majere', Elizabeth Role², Lazarus Ndiku Makewa ${ }^{3 *}$ \\ ${ }^{1}$ Mosoriot Teachers College; Kenya; ${ }^{2}$ University of Eastern Africa, Baraton, Eldoret, Kenya; ${ }^{3}$ \\ University of Eastern Africa, Baraton, Eldoret, Kenya
}

Received: May 19, 2012 / Accepted: June 26, 2012

\begin{abstract}
This study sought to determine disparities and associated factors in students' performance in Physics and Chemistry at the Kenya Certificate of Secondary Education (KCSE) examination in Nandi North District. The research objectives included determining differences in students' performance at KCSE in Physics and Chemistry, self-concept (perception) of, attitude toward, and perception of the usefulness of Physics and Chemistry as subjects. Students were classified according to gender, using a causal-comparative design. Majority of the students aged between 15 and 19 years. Three questionnaires were administered to the form four students, and KCSE results for the years 2000 - 2004 were obtained from the District Education Office. These were analyzed using descriptive and inferential statistics. We concluded that boys reflected better academic achievement as compared to the girls in both physics and chemistry. The boys and girls had comparable self-concept in physics. The girls had a higher self-concept in chemistry than the boys. This may suggest that self-concept does not influence performance in chemistry since boys still out-performed the girls in spite of the girls' higher self-concept. With regard to attitude towards chemistry and physics, the boys and girls had the same attitude, mixed and single-sex school students had comparable attitude towards physics and chemistry. An intervention regarding the level of preparedness of primary school pupils in dealing with the challenges of learning Physics and Chemistry at secondary is recommended.

Keywords: Gender, disparities, attitude, perception, chemistry, physics
\end{abstract}

\section{Introduction}

Poor performance in science subjects has been a subject of much debate among politicians, teachers, parents and education officials in Kenya and the world at large. The Kenya Certificate of Secondary Education (KCSE) is administered after a period of four years of study. KCSE is under a Kenyan curriculum called the 8-4-4 that is, eight years of primary school education followed by four years in secondary school then 4 years in tertiary level (University) of education. Three core science subjects are tested: Physics, Chemistry and Biology. A candidate has the option of choosing any two from the three subjects. Data provided in table 1 indicate candidates' performance in the 2006 and 2007 KCSE examinations in biology, physics and chemistry.

From Table 1, it is observable that the candidature for both females and males in the KCSE increased. However, candidates entered for Physics were far below that of chemistry and biology for 2006 and 2007. The number of female candidate entries in physics at KCSE increased from 21,376 to 23,767 in 2006 and 2007, respectively. Males increased from 51,123 to 59,506 . The number of female candidates was less than half of that of the male. During the same period, the mean mark for the female candidates dropped from $39.07 \%$ to $39.04 \%$ ). The male mean mark increased from $40.82 \%$ to $42.23 \%$.

Why would female candidates' perform below their male counterparts? The sources of the gender differences in educational outcomes have been the subject of considerable study and debate. One particularly contentious issue involves the possible role played by biological differences between males and females. Tests of general intelligence suggest that there are no overall differences between males and females. However, there do appear to be large gender differences with respect to aver- 
Table 1. Candidates' performance in the year 2006 and 2007 KCSE Examinations in Biology, Physics and Chemistry.

\begin{tabular}{lcccccccc}
\hline Subject & $\mathbf{2 0 0 6}$ & $\mathbf{2 0 0 6}$ & $\mathbf{2 0 0 6}$ & $\mathbf{2 0 0 6}$ & $\mathbf{2 0 0 7}$ & $\mathbf{2 0 0 7}$ & $\mathbf{2 0 0 7}$ & $\mathbf{2 0 0 7}$ \\
\hline & Female & Female & Male & Male & Female & Female & Male & Male \\
& $\begin{array}{c}\text { Nondidates } \\
\text { candion }\end{array}$ & $\begin{array}{c}\text { Mean } \\
(\%)\end{array}$ & $\begin{array}{c}\text { No. of } \\
\text { candidates }\end{array}$ & $\begin{array}{c}\text { Mean } \\
(\%)\end{array}$ & $\begin{array}{c}\text { No. of } \\
\text { candidates }\end{array}$ & $\begin{array}{c}\text { Mean } \\
(\%)\end{array}$ & $\begin{array}{c}\text { No. of } \\
\text { candidates }\end{array}$ & $\begin{array}{c}\text { Mean } \\
(\%)\end{array}$ \\
Biology & 108065 & 25.00 & 109863 & 29.84 & 118395 & 38.99 & 127516 & 44.70 \\
Physics & 21376 & 39.07 & 51123 & 40.82 & 23767 & 39.04 & 59506 & 42.23 \\
Chemistry & 111969 & 22.56 & 124932 & 27.01 & 122532 & 22.65 & 144229 & 27.69 \\
\hline
\end{tabular}

age scores on specific cognitive tasks. For example, males outperform females at visual-spatial tasks, which are thought to complement mathematical problem-solving, whiles females excel at certain verbal tasks (Neisser et al., 1996).

Data from Early Childhood Longitudinal Study indicate that, on entering kindergarten, boys and girls perform similarly on tests of general knowledge, reading and mathematics (Freeman, 2004). However, by the spring of the $3^{\text {rd }}$ grade, boys have slightly higher mathematics scores and lower reading scores. The subject-specific gender gaps appear to expand as students advance through the elementary and secondary grades. However, the National Assessment of Educational Progress data indicate that, over the next four years, each of the subject specific achievement gaps increases. Specifically, as we move from nine-year-olds to 13-year-olds, the standardized gender gaps roughly double in science and reading and become statistically distinguishable (NAEP, 1999)

A task-force report sponsored by the American Psychological Association in response to the publication of "The Bell Curve" suggested that biological factors do contribute to the gender differences in skills (Neisser et al., 1996). In particular, there are differences in male and female brain structures and in exposure to sex hormones that appear to influence the gender specific skill advantages (Kimura, 1999; Halpem, 2000; Lippa, 2002; and Cahill, 2005). However, Neisser et al. (1996) note that these biological differences interact with environmental factors that appear soon after birth.

The secondary school science subjects have been given a lot of attention by various organizations; key among them are the Forum for African Women Educationalists (FAWE), whose aim is to promote gender equity and equality in education in Africa by fostering positive policies, practices and attitudes towards girls' education and Strengthening of Mathematics and Science in Secondary Education (SMASSE), a project aimed at upgrading the capability of students in Mathematics through in-service education of teachers in response to poor performance and achievement witnessed in the Kenya Certificate of Secondary Education (KCSE) results. These interventions sought to reach students through teachers. If teachers have a negative attitude towards their teaching duties, the students would suffer.

Attitudes are generally regarded as having been learnt. They predispose an individual to action that has some degree of consistency and can be evaluated as either negative or positive (Fishbein and Ajzen, 1975; McMillen et al., 2000). Caraway (1985) revealed that mathematics competency and achievement were both positively correlated with attitude toward mathematics.
Research has argued that positive teacher attitudes contribute to the formation of positive pupil attitudes (Sullivan, 1989; Relich et al., 1994). Other studies have shown that classroom strategies used to teach a subject are influenced by teacher attitudes which, in turn, influence pupil attitudes (Carpenter and Lubinski, 1990). Research into attitudes to science subjects has explored the influence of a range of affective variables such as anxiety and self-image. Science anxiety is usually defined as a feeling of tension and anxiety that interferes with performance.

The differential representation of men and women in the scientific community has been foretold by achievement patterns evident in the elementary and secondary levels (Cakiroglu, 1999). Boys perform better than girls in achievement tests in the typically masculine areas of mathematics and science. There is a substantial body of research that documents gender differences in science and much of this research shows that males outperform females on science achievement tests (Chipman, Brush and Wilson, 1985; Fennema, 1984; Linn and Hyde, 1989; Oakes, 1990; Lee and Burkam, 1996). Observations of such differences have been reinforced by the view that boys are "naturally" better equipped to excel in science (Jacobs and Eccles, 1985). Such stereotypes that men are naturally more talented and interested in science are thought to influence the science, technology and engineering aspirations and achievements of boys, girls, men and women (Frome and Eccles, 1998; Furnham et al., 2002; Kiefer and Sekaqueptew, 2007). Some data on low female achievement has also come from the cross-cultural survey of science achievement carried out by International Evaluation of Educational Achievement (IEA). The results of the three IEA science studies (namely First International Science Study (FISS), the Second International Science Study (SISS) and Third International Mathematics and Science Study (TIMMS)) reveal that sex differences have been found in every subject area of the written science achievement tests. The sex difference favored males. The 1999 and 2003 findings reveal that boys outperformed girls and had a larger variance. The SISS conducted between 1983 and 1984 in 24 countries showed that differences in science achievement favored boys in Biology, Chemistry and Physics at all levels. Results of the 1995-1996 TIMMS show that boys had a significantly higher mean achievement than girls in both the seventh and eighth grades internationally in many countries (TIMMS, 1995-2003).

A later study on international trends in science achievement in 46 countries shows that in the US, among fourth graders in 2007 , males continued to outperform females in science with minimal differences; among eighth graders, males scored significantly higher overall than females in science (Cakiroglu, 1999; 
Mullis, Martin and Foy, 2008). The 1986 National Assessment of Educational Progress (NAEP) carried out in the United States had reported that boys outperformed girls in sciences achievement and the gender gap increased as students progressed in school. A later assessment by NAEP in 2005 revealed that males outperformed females in science achievement in grades 4,8 and 12. Females at all levels made relatively little gains in their average science scores since 1996. In most cases by grade 11, the areas of largest male advantage were physics, chemistry, earth science and space science (Kahle and Meece, 1994). In the final year of secondary school, males had a significantly higher achievement in scientific literacy than females in all participating countries (EU, 2009).

The scenario is not any different in Africa. In Uganda, for example, the trend in academic excellence has shown that boys perform better than girls in chemistry. However, a study was carried out to determine if there were any gender differences in the performance of chemistry skills among senior six girls and boys in selected secondary schools in Kampala. A total of 50 students participated ( 25 boys and 25 girls). Although there were no differences in the students' ability to manipulate apparatus and report results, girls had poor self confidence in their ability as most of them believed that boys were better (Ssempala, 2005). In Kenya, similar results are evident. IPAR (2003) study on the performance of students in KCSE revealed that in science subjects the percentage gap in Physics in the three districts under study was $5 \%$ in Kiambu, $8 \%$ in Bungoma, $8.7 \%$ in Kisumu. The same trend was observed in Chemistry and Biology. In terms of equity, women have not attained educational equity in many African countries and they are systematically under-represented in scientific and technical disciplines (Adams and Kruppenbach, 1986 as cited in Frazier, 1999). In these countries, the number of women enrolled in science based training and those involved in science based professions are among the lowest in the world (Frazier, 1999). Elsewhere, research does show some decline in gender differences in science achievement in some countries but with low female representation in science related fields (Jacobs, 2005).

Males continue to surpass females in the number of under-

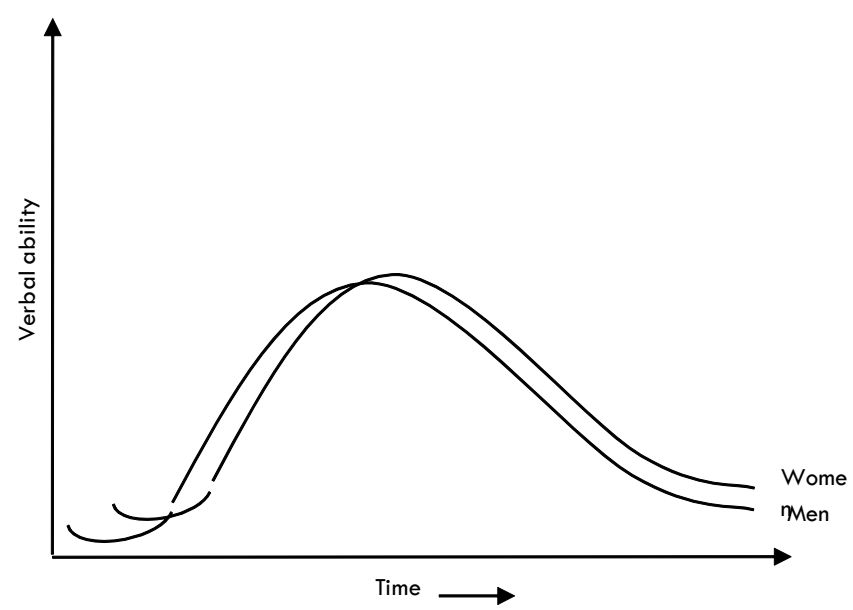

Figure 1. Verbal Abilities of Men and Women. (Source: Psychology of Sex Differences by Maccoby and Jacklin, 1974).

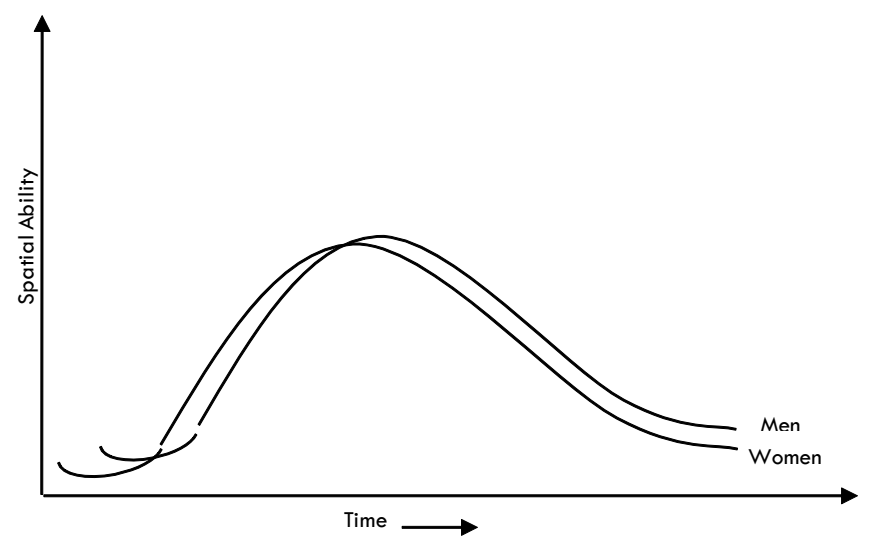

Figure 2. Spatial Abilities of Men and Women. (Source: Psychology of Sex Differences by Maccoby and Jacklin, 1974).

graduate degrees awarded in science and engineering fields especially in computer science, physical science and engineering (National Science Foundation, 2005). The share of females enrolled in science was below $20 \%$ in Botswana, Gambia, Guinea and Nigeria. The proportion in engineering was below $10 \%$ in Ghana and Swaziland (UNESCO, 2008). Gender differences in achievement have been attributed to a variety of biological and environmental factors in what usually comes down to nature versus nurture debate (Dee, 2005). Some studies show that any biological differences interact with environmental factors that appear soon after birth (Naiser et al., 1996). Researchers who emphasize environmental (nurture) factors often blame societal expectations based on commonly held myths about gender. Johnson and Murphy (1984) found that societal expectations for men and women result in different expectations in the early socialization of girls and boys that are reinforced by appropriate role models from real life in the media and text books. Both male and female teachers have a negative attitude towards girls' abilities to perform well in mathematics and science. Teachers cite girls' fear of the subjects, lower determination and lower intelligence when compared to boys. Bali (1997) found that the majority of teachers believed that boys would join the university to train as doctors, engineers and architects while girls were only capable of being tailors, teachers and secretaries. Generally, teachers usually interact differently with boys and girls and some evidence suggests that students benefit academically from having teachers who are of the same gender as themselves (Dee, 2007).

\section{Conceptual Framework}

Maccoby and Jacklin (1974) argue that females are more verbally fluent than the males while males have more acute visual-spatial abilities than females.

The brain is functionally divided into two hemispheres: the right and the left hemisphere. The left hemisphere is concerned with paintings, poetry, musical compositions, speech and language. The left hemisphere processes information systematically and sequentially. The right hemisphere, on the other hand, is con- 
cerned with processing of visual and spatial skills, manipulation of objects and perceiving music. The right hemisphere processes information simultaneously and as a whole. For the right-handed persons, the left hemisphere, according to the work titled A primer of psychophysiology by Hasset (1978), is concerned with verbal and logical thinking while the right is concerned with spatial, intuitive thinking. The left-handed persons are more complicated because mixed cerebral dominance is evidently causing the hemispherical functions not to be clear-cut.

The study by Maccoby and Jacklin (1974) adds that females have a larger size of Wernicke's Area which is a major language comprehension center in the brain. Additionally, the corpus callosum, a bundle of fibers that link the left hemisphere to the right one, is larger in the female than it is in the male.

In the book Foundations of psychology written by Robinson and Uttal (1983), it is explained that animals deprived of patterned visual stimulation from birth will have irreversible perceptual disturbance and will display degenerative processes throughout the visual system. An impoverished animal has on average a relatively less massive brain while the animal that is adequately nourished will have a larger brain.

Current theories suggest that learning is due to the strengthening of already formed synapses. This implies that practice or repeated stimulation established reverberatory electrical circuit among the neural units that were initially activated. While the males had a slight edge over females in spatial ability, the difference was small. The operant conditioning theory articulated by B.F. Skinner emphasizes the importance of repeated stimulus exposure during the learning at the early ages of children.

An investigation entitled 'Are girls a disadvantaged group?' conducted by Rowlands (1976) on 2,787 boys and 5,963 girls compared their academic performance at ' $D$ ' grade and ' $A$ ' grade levels in the 1974 Higher Schools Certificate Examination in Biology in Australia. They established that boys performed better at both pass and distinction levels at 0.05 level of significance.

The book titled Women in Science: Communications by Smithers and Collings (1982) bears relevance to the current study through the debate regarding the relative merits of co-educational and single sex schools which had been quiescent since Dale's Massive review in the 1960's. The debate had come to life again around the claim that mixed grouping put girls off the science subjects and mathematics.

Citing the work of Piaget (1981) the PhD dissertation titled Effects of Values Integration and Affective Learning in Mathematics by Role (1995) raises a relevant argument that cognitive and affective domains were inseparable because each had an important effect on the other. In schools, most teachers neglect to plan for the affective variables but dwell on the cognitive domain.

The PhD dissertation by Role (1995) is important to this study because it outlines the importance of educating the whole person by focusing intently on development of healthy self-concepts, security, love, respect and feelings. Additionally, beliefs, attitudes and emotions play important roles in the process of learning. From the foregoing literature, it is evident that the affective domain has an important role to play in learning.
The work by Mandler (1975) further expounds on the development of cognitive theories. His cognitive theory of development was based on the foundation of information-processing theory. It stresses the fact that interfering with a student who was in the process of completing an action sequence aroused the automatic nervous system and frustration would easily set in and lead to underperformance (Hummel and Huitt, 1994).

This study sought to determine disparities in the students' performance in Physics and Chemistry at KCSE level. It also set out to determine the factors associated with the disparities in the performance in physics and chemistry at the KCSE level Nandi North District.

\section{Method}

This study employed causal-comparative design. This type of design was chosen because it was considered appropriate in informing the study with detailed information from respondents. Correlational design was more useful in testing the hypothesis.

\section{Sampling and Sampling Procedures}

The population for the study included all 54 secondary schools in Nandi North District. The target population had three categories of schools as indicated in table 2.

Purposive random stratified sampling technique was used in the selection of schools. A list of all schools in Nandi North District was obtained from the District Education Office and used to draw up the sample size. Purposive sampling was used to eliminate those schools in Nandi North District that had not completed the KCSE during 2000 to 2004 . Stratified sampling was then used to ensure that all types of schools in the six different divisions of the district were covered in the sample. The schools were stratified into boys', girls', and mixed schools. The sample obtained was also classified into rural and urban schools. A sample that represented $30 \%$ of the different strata was then drawn up at random. Table 3 shows type and location of sampled schools. Form four (students who were in their last year in secondary school) Physics and Chemistry students were targeted in the selected schools. The sample of 300 students for this study consisted of $33 \%$ of boys' schools, $33 \%$ of girls' schools and $33 \%$ of co-educational schools. In addition, 146 form four Biology students were randomly picked from the 20 schools used in the study and asked to answer an open-ended questionnaire seeking to establish their reasons for not choosing Physics or Chemistry. Thus, a total of 446 students constituted the sample.

\section{Research Instruments}

The researchers used one questionnaire for students who studied physics, another for those who took chemistry, and the third for those who studied Biology without Physics or Chemistry. The questionnaires for physics and chemistry consisted of close-ended questions modeled on a Likert-type of scale with the following scale: strongly agree (5), agree (4), disagree (3), strongly disagree (2), and undecided (1). The Biology questionnaire had open-ended questions that allowed the respondents 
to express their opinions about the barriers to academic performance in physics and chemistry.

The performance rating for the science teachers was based on a six-point scale:

$\begin{array}{ll}5- & \text { Strongest } \\ 4- & \\ 3- \\ 2- \\ 1- \\ 0-\end{array} \quad \begin{aligned} & \text { Average } \\ & \text { Weakest } \\ & \text { No available information }\end{aligned}$

\section{Methods of Data Collection}

Data was obtained from three questionnaires answered by 408 respondents. The respondents were form four students who studied Physics, Chemistry and Biology in the year 2006.

The questionnaires were based on the objectives of the study, which sought to establish the effects of the following variables on academic achievement:

i. Self-concept of respondents in Physics and Chemistry.

ii. Attitude towards Physics and Chemistry.

iii. The performance rating of the Physics and Chemistry teacher.

iv. The respondents' perception of the usefulness of Physics and Chemistry.

v. Self-concept, attitude and perception of usefulness of Physics and Chemistry.

Respondents who studied Chemistry at KCSE level answered the first questionnaire. The second questionnaire was administered to respondents who studied Physics at KCSE level.

The third questionnaire was administered to 146 form four students who studied biology instead of Physics or Chemistry. The third questionnaire sought to establish reasons why respondents did not opt to study Physics or Chemistry.

Examination of Physics and Chemistry at KCSE level entails a practical and a theory paper. The marks obtained in both papers for each subject are combined and a percentage calculated for the purpose of grading that subject. The award of grades depends on the overall performance in each subject in a given year. The grading is done on a 12-point scale. The highest mark is graded as A, while the lowest is awarded grade E. An A carries an equivalent of 12 points and an $E$ only 1 (one) point.

\section{Development of Research Instruments}

The questionnaire was adapted from Role's PhD 1995 dissertation, titled Effects of Integration on College Students' Cognitive and Affective Learning in Mathematics. T-test was used to compare differences between two groups of students. To establish the relationship between the teacher's gender and attitude, self-concept and the perception of the usefulness, point-biserial correlation was used. This was a special case of Pearson's Product Moment Correlation, which is used when the independent variable is dichotomous and the dependent variables are scores.
To establish the relationship between the teacher's performance rating and attitude, self-concept and the perception of the usefulness, Pearson's Product Moment Correlation coefficient was used because the independent and the dependent variables were scores and the correlation was obtained between one independent and one dependent variable.

The questionnaire consisted of statements on students' attitude, self-concept, perception of usefulness of the subjects, and teacher evaluation using the Likert-type of scale. This section sought answers on the respondents' perceptions on relationships between the variables that were being investigated.

\section{Reliability of the Instrument}

To establish reliability of the questionnaire, the Internal Consistency Technique in SPSS package was used. This technique tested the reliability of items using the group of 170 respondents only once. Reliability was then established using Cronbach's Alpha Coefficient, which was computed to determine how items correlated to one another. A reliability coefficient of 0.7919 was obtained for the items relating to students' self-concept, 0.7093 for those relating to students' perceptions of the usefulness of chemistry and physics, 0.8950 for items relating to students' attitude. The reliability coefficients obtained were all acceptable values in social sciences for research instruments.

\section{Administration of Instruments}

The Ministry of Education, Science and Technology granted the permit for the study. Personal contact was made with the school principals, physics teachers and form four students of the selected schools in seeking their co-operation. The researchers collected data by visiting the schools to administer the questionnaires. The percentage return rate of the questionnaires was $91.5 \%$ (408 out of 446 questionnaires were returned duly filled).

The researchers also obtained the KCSE examination results of the selected schools for a period of five years (2000-2004) from Nandi North District Education Office. They also used the results obtained as a measure of academic performance by students in Physics and Chemistry in the study area.

\section{Data Analysis Procedures}

After coding, the data was analyzed using the Statistical Package for Social Sciences (SPSS). T-test was used to compare differences in the mean scores obtained from the performance of students in Physics and Chemistry. Pearson's Product Moment Correlation coefficient was used to relate paired variables of attitude, self-concept, teachers' performance rating, teachers' gender, and perception of the usefulness of Physics and Chemistry. The analyses were used to establish relationships between variables. The level of significance used in this study was 0.05 , which is the level deemed acceptable for social science research (Best, 1991). 
Table 2. Analysis of the students' self-concept in physics and chemistry by gender.

\begin{tabular}{llllllll}
\hline Variable & Subject & Gender & N & Mean & $\begin{array}{l}\text { Standard } \\
\text { Deviation }\end{array}$ & t & Prob. \\
\hline \multirow{3}{*}{ Self concept } & \multirow{2}{*}{ Chemistry } & Male & 160 & 37.8500 & 7.35121 & \multirow{2}{*}{1.975} & \multirow{2}{*}{0.049} \\
& & Female & 95 & 39.7053 & 7.08140 & & \\
& \multirow{2}{*}{ Physics } & Male & 159 & 41.5597 & 6.45588 & \multirow{2}{*}{0.235} & 0.814 \\
\hline
\end{tabular}

Table 3. Analysis of the students' attitude towards physics and chemistry by gender.

\begin{tabular}{llllllll}
\hline \multirow{2}{*}{ Variable } & Subject & Gender & $\mathbf{N}$ & Mean & $\begin{array}{l}\text { Standard } \\
\text { Deviation }\end{array}$ & t & Prob. \\
\hline \multirow{4}{*}{ Attitude } & \multirow{2}{*}{ Chemistry } & Male & 161 & 48.8944 & 7.97543 & \multirow{2}{*}{1.919} & \multirow{2}{*}{0.056} \\
& & Female & 96 & 50.8021 & 7.24405 & & \\
& \multirow{2}{*}{ Physics } & Male & 159 & 51.2453 & 7.33357 & \multirow{2}{*}{0.841} & 0.401 \\
& & Female & 92 & 50.4130 & 7.91598 & & \\
\hline
\end{tabular}

Table 4. Analysis of the students' perception of the usefulness of Physics and Chemistry due to gender.

\begin{tabular}{|c|c|c|c|c|c|c|c|}
\hline \multirow[b]{2}{*}{ Variable } & \multirow[b]{2}{*}{ Subject: } & \multirow[b]{2}{*}{ Gender } & \multicolumn{5}{|c|}{ Standard } \\
\hline & & & $\mathbf{N}$ & Mean & Deviation & $t$ & Prob. \\
\hline Perception of & Chemistr & y: Male & 160 & 40.8939 & 4.93938 & مמ2 0 & 0842 \\
\hline \multirow[t]{3}{*}{ usefulness } & & : Female & 94 & 41.0319 & 5.9144 & 0.200 & 0.842 \\
\hline & Physics & : Male & 159 & 40.9308 & 6.65527 & -0635 & 052 \\
\hline & & : Female & 91 & 41.4615 & 5.81054 & & \\
\hline
\end{tabular}

\section{Results and Discussion}

(a) Do students differ in self-concept in Physics and Chemistry in terms of gender?

Table 4 presents the comparison of boys' and girls' self-concept in Physics and Chemistry. From table 4, it is noticeable that the female students had a better self-concept (perception) in Chemistry than the male students. There was a statistically significant difference between male and female students in their self-concept in Chemistry. On the other hand, there was no statistically significant difference in the self-concept of male and female students in physics. The mean for self-concept of both groups is almost the same.

The above findings contradict Marland (1983) study titled Sex differentiation and schooling, which states that girls tended to be less confident in their ability to succeed in challenging intellectual tasks. In another study by Reyes (1984) entitled Affective variables and Mathematics education published in the Elementary School Journal, there is agreement on the findings of Marland (1983) that the girls' lack of confidence emanated from uncertainty of success when tasks performed were familiar and when the past performance feedback had been infrequent or ambiguous.

(b) Do students differ in attitude towards physics and Chemistry in terms of gender?

Table 5 shows that female students had a more positive attitude towards Chemistry than the male students. On the other hand, the male students had a more positive attitude towards Physics than the female students. However, the differences were not statistically significant. The mean attitude scores of both groups show that these students had positive attitude toward Physics and Chemistry.

This result contradicts statements made in a paper presented to teachers at Kenya Institute of Education on April 30, 1997 by Mutinda which asserted that there was a negative attitude to science subjects and mathematics among students. The Daily Nation published an article entitled Alarming statistics on Mathematics performance which stated that teachers contributed to lowering of the girl child's attitude towards sciences (Kilemi, 2002). The daily newspaper added that the SMASSE program aimed at removing the negative attitude as it contributed to poor performance.

(c) Do students differ in their perception of the usefulness of Physics and Chemistry in terms of gender?

The results presented in table 6 show that female students had a slightly better perception of the usefulness of both Physics and Chemistry than the male students but the difference was not statistically significant.

The foregoing discussions, comparing the self-concept in, attitude toward, and perception of usefulness of Physics and Chemistry of boys and girls, where the girls have equally positive self-concept, attitude and perception of usefulness as boys, suggest a possible reason why the girls were able to perform as good as the males in Chemistry and in Physics on some occasions. 
Table 5. A comparison of students' attitude, self-concept and perception of the usefulness of physics and chemistry in terms of gender.

\begin{tabular}{lllllll}
\hline Variable & Gender & N & Mean & Seviation & t & Prob. \\
\hline Attitudes towards Chemistry & Male & 159 & 48.9182 & 8.02210 & & 0.000 \\
Attitude towards Physics & Male & 159 & 51.2453 & 7.3335 & -3.667 & 0.442 \\
Attitudes towards Chemistry & Female & 87 & 51.2644 & 6.96246 & 0.772 & 0.453 \\
Attitude towards Physics & Female & 87 & 50.4253 & 8.08333 & & \\
Self concept in Chemistry & Male & 158 & 37.8734 & 7.35257 & & 0.000 \\
Self concept in Physics & Male & 158 & 41.5886 & 6.46611 & -5.958 & 0.043 \\
Self concept in Chemistry & Female & 86 & 39.9070 & 7.12515 & -.2050 & 0.916 \\
Self concept in Physics & Female & 86 & 41.8023 & 6.45130 & & \\
Perception of usefulness of Chemistry & Male & 158 & 40.9620 & 4.92994 & & \\
Perception of usefulness of Physics & Male & 158 & 40.051 & 6.66848 & 0.106 & 0.963 \\
Perception of usefulness of Chemistry & Female & 85 & 41.2706 & 5.63236 & -0.173 & 0.863 \\
Perception of usefulness of Physics & Female & 85 & 41.4118 & 5.96876 & & \\
\hline
\end{tabular}

The article Gender disparities in higher education: nature, extent and the way forward published in the journal The African Symposium, authored by Bunyi (2004), suggests that socio-cultural beliefs and practices militate against the education of girls and women in their university careers. This suggestion is inconsistent with what exists at the school level. According to the case study titled Female marginalization in vocational and Technical education in Kenya by Ngau (1993), schools, training institutions and universities lack career guidance programs and trained personnel who can counsel students on subjects and course choices that are relevant to their career expectations and potential job opportunities. The girls have a higher perception of the usefulness of Physics and Chemistry as compared to boys because girls handle many tasks at home that involve the use of Physics and Chemistry concepts.

An analysis comparing students' attitude toward, self-concept in and perception of the usefulness of Physics and Chemistry is shown in table 7. Table 7 shows that the male students had a significantly better attitude towards Physics than towards Chemistry. The female students, on the contrary, had a better attitude towards Chemistry than towards Physics, although the difference is not statistically significant. The self-concept of both female and male students in Physics was much higher than they had in Chemistry.

The perception of usefulness of Chemistry was just slightly higher than the usefulness of Physics, as far as the male students were concerned. The perception of the usefulness of Physics was slightly higher than the usefulness of Chemistry for the female students. However, these differences were not statistically significant.

The above scenario presents the boys as students set to do well in both Physics and Chemistry. Male students perform better in both Physics and Chemistry than their female counterparts. It should be noted, however, that the girls have a lot of potential to do well in Physics and Chemistry because they have comparable mean scores, even slightly higher, than those of the boys in attitude, self-concept and the perception of the usefulness of Physics and Chemistry. The students' self-concept, attitude and usefulness show girls can excel in Physics and Chemistry if en- couraged positively by their parents, teachers, their peers and other stakeholders.

\section{Conclusions and Recommendations}

From the results, this study concludes that boys reflected better academic achievement as compared to the girls in both Physics and Chemistry. The boys and girls had comparable selfconcept in Physics but a higher self-concept in Chemistry than the boys. This may suggest that self-concept does not influence performance in Chemistry since boys outshone the girls in spite of the girls' higher self-concept. With regard to attitude towards Chemistry and Physics, the boys and girls had the same attitude, mixed and single-sex school students had comparable attitude towards Physics and Chemistry.

Teaching and learning should be organized to take account of individual student differences and teachers should be educated to understand the origins and implications of gender differences and to develop pedagogical skills to accommodate and modify these as appropriate. Teachers should be trained in skills to use materials within a critical gender framework, thus enabling young people themselves to study materials critically from a gender perspective. Textbooks and other curricular materials should be critically evaluated for their gender inclusivity. When science curricula are presented in a framework of social issues, using contexts familiar to both girls and boys, girls are readily involved.

The results of this study indicate that there is a great deal of work still to be done in education to address the different science experiences and views of male and female students in schools.

Based on these findings, the following recommendations are made:

1. Deliberate efforts should be made by teachers to guide students in their choice of appropriate science subjects for study so that they may train into the professionals they wish to be.

2. Teachers should work towards the development of posi- 
tive attitude, positive self-concept and high perception of the usefulness of Physics and Chemistry in students, by planning for the affective domain in their lessons.

3. The teachers should endeavor to demystify mathematical calculations encountered in Physics by the students through systematic assignments that are motivating to students. These assignments could be based on the theoretical as well as practical activities. Teachers should constantly be updated on how they are rated in their teaching subjects as this has an impact on the development of students' confidence and positive attitude towards Physics and Chemistry, as well as on student perception of the usefulness of the two science subjects.

4. School principals, teachers, policy makers, researchers, parents and the community should build common goals to enhance student achievement in Physics and Chemistry. This could be done through a regular review of learning conditions, school leadership, curriculum and instruction or organization and management at the school level.

Further research could be done regarding the level of preparedness of primary school pupils in dealing with the challenges of learning Physics and Chemistry in secondary school.

\section{References}

Adams M and S Kruppenbach (1986) "Some Issues of Access and Eqvity in the Education of African Females: Progress and Prospects." East Lansing, Michigan: Michigan State University. Office of Women in International Development (WIN). WIN Working Paper 116.

Bali SK (1997) A comparative study of antecedents of gender specific school wastage rates in Kenya. Nairobi: Academy of science publishers.

Best WJ (1991) Research in education. U.S.A.: Prentice-Hall, Inc.

Bunyi GW (2004) Gender disparities in higher education in Kenya: nature, extent and the way forward. The African symposium, 4, 1.

Cahill L (2005) "His Brain, Her Brain." Scientific American 292 (5):4047.

Cakiroglu J (1999) Gender differences in the science classroom. Hacettepe Universitesi Egitim Fakultesi Dergisi 16-17: 123-133.

Carpenter T and C Lubinski (1990) Teachers' attributions and beliefs about girls, boys and mathematics. Educational Studies in Mathematics 21, 55-69.

Caraway SD (1985) Factors influencing competency in mathematics among entering elementary Education majors. Unpublished manuscript, University of South Alabama. (ERIC Reproduction Service Document No. ED260941).

Chipman SF, L Brush, and DD Wilson (1985) Eds. Women and mathematics: Balancing the equation. H.J: Lawrence Erlbaum Associates.

Dee DS (2005) Teachers and the gender gaps in student achievement. Working Paper No 1660. National Bureau of Economic Research.

Dee DS (2007) Teachers and the gender gaps in student achievement. Journal of Human Resources 42 (3): 528-554.

European Union Report (2009).

Fennema E (1984) Girls, women and mathematics. In E. Fennema (Ed.). Women and Education: Equity or Equality? Berkley, CA: McCutchun Publishing Co.

Fishbein M and I Ajzen (1975) Belief, attitude, intention and behavior: An introduction to theory and research. Reading, Mass.: AddisonWesley Frome, P. M., \& Eccles J. S. (1998). Parents' influence on children's achievement-related perceptions. Journal of Personal Social
Psychology 74: 435-452.

Frazier S (1999) A psychological study of mathematics attitudes and achievement among female/ women students. Kouasi Working Paper NO 268. University of Michigan.

Freeman CE (2004) Trends in Educational Equity of Girls and Women: 2004. NCES 2005-016, U.S. Department of Education, National Center for Education Statistics. Washington, D.C.: GPO.

Frome PM and JS Eccles (1998) Parents' influence on children's achievement-related perceptions. Journal of Personality \& Social Psychology 74: 435-452.

Furnham A, E Revees, and S Budhani (2002) Parents think their sons are brighter than their daughters: Sex differences in parental self estimation and estimations of their children's multiple intelligences. Journal of General Psychology, 163: 24-39.

Halpem DF (2000) Sex Differences in Cognitive Abilities, 3rd Edition. Mahwah, N.J.: Lawrence Eribaum Associates.

Hassett J (1978) A Primer of psychophysiology. New York: W. H. Freeman and Company.

Hummel J and W Huitt (1994) What you measure is what you get. GaASCD Newsletter: The Reporter 10-11.

Institute of Policy, Research and Analysis (2003) Access and participation in secondary school education in Kenya: Emerging issues and policy implications. IPAR Policy Brief 9 (6): 1-4.

Jacobs JE and JS Eccles (1985) Gender differences in math ability: The impact of media reports on parents. Education Researcher 14: 20-25.

Jacobs JE (2005) Twenty-five years of research on gender and ethnic differences in math and science career choices: What have we learned? New Directions for child and adolescent development 110: 85-94.

Johnson S and P Murphy (1984) The underachievement of girls in physics: towards explanations, European Journal of Science Education 6: 399-409.

Kahle JB and J Meece (1994) Research on gender issue in the science classroom. In Handbook of Research on Science Teaching and Learning, Gabel (Ed.) New York: Mac Millan Publishing Company.

Kiefer AK and D Sekaqwaptewa (2007) Implicit stereotypes, gender identification and math related outcomes:A prospective study of female college students, Psychological Science 18:13-18.

Kimura D (1999) Sex and Cognition. Cambridge and London: The MIT Press.

Lee VE and DT Burkam (1996) Gender differences in middle grade science achievement: Subject domain, ability level, and course emphasis. Science Education 80 (6): 613-650.

Linn MC and JS Hyde (1989) Gender mathematics and science. Educational Researcher 18: 17-19.

Lippa RA (2002) Gender, Nature, and Nurture. Mahwah, N.J.: Lawrence Eribau.

Maccoby E and CN Jacklin (1974) The psychology of sex differences. Palo Alto, California: Stanford University Press.

Mandler G (1975) Mind and Emotion. New York: Wiley. Reprint edition: Melbourne, Florida: Krieger, 1982.

Marland M (1975) The craft of the classroom: a survival guide to classroom management in the secondary school. London: Heinemann Educational Publishers.

Marland M (1983) Sex differentiation and schooling. United Kingdom: Heinemann Educational Publishers.

McMillen M. KJ Seastrom, RH Gruber, DJ McGrath, and BA Cohen (2000) Qualification of the public school teacher workforce: Prevalence of out of-field teaching 1987-88-1999-2000. Education Statistics Quarterly.

Mullis IVS, O Martin, and P Foy (2008) TIMSS 2007 International Report: Findings from IEAs Trends in International Mathematics and 
Science Study at the Fourth and Eighth Grades. Chestnut Hill, MA:TIMSS\&PIRLS International Study Center, Boston College.

National Assessment of Educational Progress (1999).

National Science Foundation (2005) Women Minorities and Persons with disabilities in science and engineering.

Neisser V, G Boodoo, TJ Bouchard, AW Boykin, N Brody, SJ Cesi, DF Halpern, JC Loehin, R Perlof, RJ Sternberg, and S Urbina (1996) Intelligence: Knowns and unknowns. American Psychologist 51(2): 77-101.

Neisser U, B Gwyneth, J Thomas, A Bouchard, AW Boykin, B Nathan, SJ Ceci, DF Halpern, JC Loehlin, R Perloff, RJ Stemberg, and S Urbina (1996) Intelligence: Knowns and Unknowns. American Psychologist 5 (2): 77-101.

Ngau MM (1993) Female marginalization in vocational and technical education in Kenya: a case study. Nairobi, Kenya.

Oakes J (1990) Opportunities, achievement and choice: Women and minority students in science and mathematics. Review of Research in Education 16: 153-222.

Relich J, J Way, and A Martin (1994) Attitudes to teaching mathematics: Further development of a measurement instrument. Mathematics
Education Research Journal 6 (1): 56-69.

Reyes LH (1984) Affective variables and mathematics education. The Elementary School Journal 84 (5): 558-581.

Role EM (1995) Effects of values integration on college students' cognitive and affective learning's in mathematics. Unpublished Ph.D. Dissertation, University of the Philippines, Quezon City.

Robnison D and W Uttal (1983) Foundations of Psychology, New York: Macmillan.

Rowlands RG (1976) Are girls a disadvantaged group? Australian Journal of Education.

Smithers A and J Collings (1982) Women in science. Communications. Manchester: University of Manchester.

Ssempala F (2005) Gender differences in the performance of Chemistry practical skills among senior six students in Kampala. Boston: Bola Baton.

Sullivan $P$ (1989) The impact of a pre-service mathematics education on beginning primary teachers. Research in Mathematics Education in Australia, August, 1-9.

Third International Mathematics and Science Study (1995-2003). UNESCO (2008) Regional Overview: Sub-Saharan Africa. 